\section{Cinc segles de desigualtat i transformació socioeconòmica en l'àrea de Barcelona, 1451 - 1880}

Joana Maria Pujadas-Mora, Centre d'Estudis Demogràfics, Universitat Autònoma de Barcelona; Gabriel BreaMartínez, Department of Economic History, Lund University (Suècia)

La distribució desigual de la riquesa és un tema que preocupa cada vegada més a les societats contemporànies però té fortes arrels en el passat. Diversos autors han traçat els orígens d'aquesta desigualtat reconstruint sèries històriques, recopilant i harmonitzant dades de fonts i registres amb una cobertura territorial i temporal desigual (Milanovic et al. (2011), Alfani (2015) Piketty (2014 i 2020)). Pocs llocs en el món disposen de sèries estadístiques que permetin reconstruir els patrons de desigualtat socioeconòmica d'acord amb una única font documental. Barcelona i la seva àrea són un d'aquests llocs. La Barcelona Historical Marriage Database, creada en el marc del projecte Advanced Grant Five Centuries of Marriages dirigit per la Prof. Anna Cabré, ha possibilitat analitzar per a un període de cinc segles la distribució de la riquesa a partir de les taxes fixades als matrimonis celebrats en la seva Diòcesi entre 1451 i 1880. En aquest número de Perspectives Demogràfiques examinem l'evolució de la desigualtat des de l'Antic Règim fins a la consolidació de la industrialització, la concentració de la riquesa i la composició i substitució de les elits econòmiques de l’àrea de Barcelona.

\section{MESURAR LA DESIGUALTAT AMB LA BARCELONA HISTORICAL MARRIAGE DATABASE}

La Barcelona Historical Marriage Database (BHMD) compila les dades impositives i ocupacionals proporcionades pels Llibres d'Esposalles de la Diòcesi de Barcelona que abasten des 1451 a 1905. Les esposalles graven els matrimonis que es contrauen a la Diòcesi de Barcelona amb la finalitat de finançar la construcció i posterior manteniment de la Catedral de Barcelona. D’aquesta manera, la BHMD conté informació fiscal de més de 600.000 matrimonis celebrats entre els segles XV i XX en aproximadament 250 parròquies, distribuïdes en les actuals comarques del Baix Llobregat, Barcelonès, Maresme i Vallès Occidental. Aquestes comarques inclouen grans ciutats com Barcelona, Mataró, Sabadell i Terrassa. Per a cada matrimoni coneixem el nom i cognoms dels contraents, lloc de residència / parròquia de celebració, ocupació del marit i l'import de la taxa o impost matrimonial, informació que pot variar al llarg del temps.

Cada matrimoni pagava una taxa que variava segons l'estatus socioeconòmic dels contraents. Aquesta se classificava en grans grups: 1) Noblesa, 2) Militars, 3) Ciutadans honrats (aquells que podien ocupar càrrecs públics), 4) Comerciants, doctors en lleis o en medicina, 5) Mestres gremials, 6) Pagesos i artesans, i 7) els que es consideraven pobres. Els pobres, encara que declaressin una ocupació, estaven exempts del pagament. L'impost es registrava en lliures, sous i diners, unitats de compte comuns fins a la primera meitat de segle XIX.

FIGURA 1. Índex de Gini per a l'àrea de Barcelona, 1481-1880

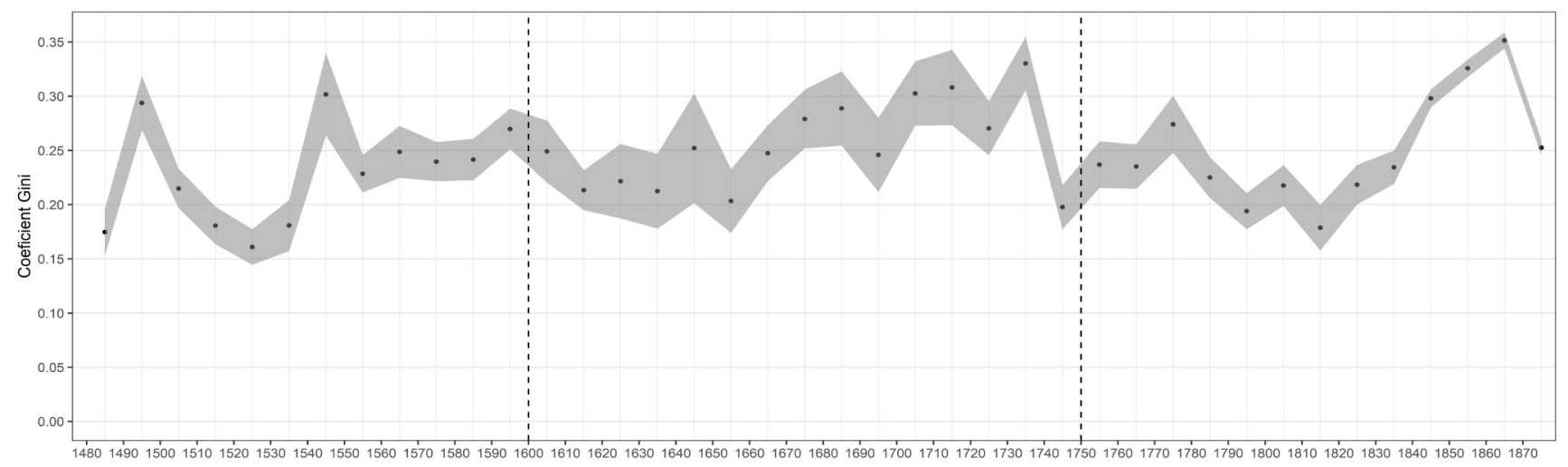

Nota: Per a l'estimació de l'índex de Gini a partir del concepte de 'capacitat contributiva' les ocupacions / estatus socials han estat transformades en un valor numèric continu amb la classificació internacional d'estratificació social / ocupacional HISCAM (Lambert et al., 2013). Font: BHMD i Brea-Martínez, Gabriel; Pujadas-Mora, Joana Maria (2019) "Estimating long-term socioeconomic inequality in southern Europe: The Barcelona area, 1481-1880". European Review of Economic History, 23 (4): 397-420. 
Per estimar la capacitat contributiva de cada individu combinem l'impost pagat (estatus econòmic) i el grup socio-ocupacional al qual pertanyia (estatus social) (Kendrick 1939; Álvarez i Ramos Palència, 2018; Brea-Martínez i Pujadas-Mora, 2019). Una vegada fixada la capacitat contributiva de cada matrimoni, calculem dos indicadors de desigualtat: el coeficient de Gini i el de Theil. Aquest darrer indicador permet descompondre l'aportació de cada grup social a la desigualtat general. Endemés, a partir de la suma dels impostos pagats en cada període, estimem el percentatge de riquesa que acumula l'1\% més ric.

\section{LA DESIGUALTAT JA ERA IMPORTANT EN ELPASSAT}

La Figura 1 mostra l'evolució de la desigualtat econòmica a l'àrea de Barcelona entre 1481 i 1880 estimada a partir de l'índex de Gini amb la informació proporcionada per la Barcelona Historical Marriage Database. Quan el valor de l'indicador de Gini és igual a o significa que la riquesa es distribueix equitativament. Quan l'índex és igual a 1 implica que tota la riquesa estaria en mans d'una sola persona, en el nostre cas d'una sol matrimoni. Com palesa la Figura 1, els nivells de desigualtat en l'àrea de Barcelona durant l'època preindustrial (abans del segle XIX) eren significatius i semblants als d'altres països com Itàlia, Països Baixos o Portugal (Reis, 2016; Alfani 2015; Van Zanden, 1995).

Pel que fa a l'evolució de la desigualtat en el temps, destaquem 3 períodes (també indicats a la Figura 1) que coincideixen a grans trets amb les fases de desenvolupament econòmic a Catalunya. El primer període s'emmarca entre 1481 i 1649 i es caracteritza per una baixa desigualtat i una posterior estabilització en els nivells de la mateixa. Aquesta progressió coincideix amb l'estancament econòmic de Catalunya després de la Guerra Civil (1462-1472) i la revolta dels remences. A més, les recurrents crisis de mortalitat causades per diferents episodis de pesta, especialment el brot que es produí entre 1647 i 1652, sens dubte van contribuir a reduir la desigualtat.

El segon període, de 1650 a 1749, es caracteritza per un augment considerable de la desigualtat com a conseqüència de la reorganització política i econòmica després de les crisis del període anterior. Des d'una perspectiva econòmica, es tracta d'una fase de creixement, forta expansió vitícola i un nou tipus de contracte emfitèutic -rabassa morta- pel qual el pagès tenia el domini útil de la terra mentre els ceps estiguessin vius. Això va comportar fortes transformacions ocupacionals i socials acompanyades d'una mobilitat social important. El nivell màxim de desigualtat al llarg d'aquest període s'observa al voltant de 1740 que coincideix amb el desenvolupament de formes de protoindustrialització en moltes àrees rurals, així com amb l'establiment de les primeres fàbriques d'indianes a Barcelona.

En el tercer i darrer període, entre 1750 i 1880, s'observa com la desigualtat va disminuir fins a 1833, data que tradicionalment marca l'inici de la industrialització a Catalunya, excepte durant el període de la Guerra del Francès (1808-1814). A partir d'aquest moment i fins a 1880, la desigualtat gairebé es va duplicar coincidint amb un nombre creixent de matrimonis que reberen la llicència matrimonial gratuïtament, bàsicament jornalers i treballadors involucrats en el procés d'industrialització.

FIGURA 2. Descomposició de la desigualtat a partir de la contribució dels grups socials en l'àrea de Barcelona, 1481-1880
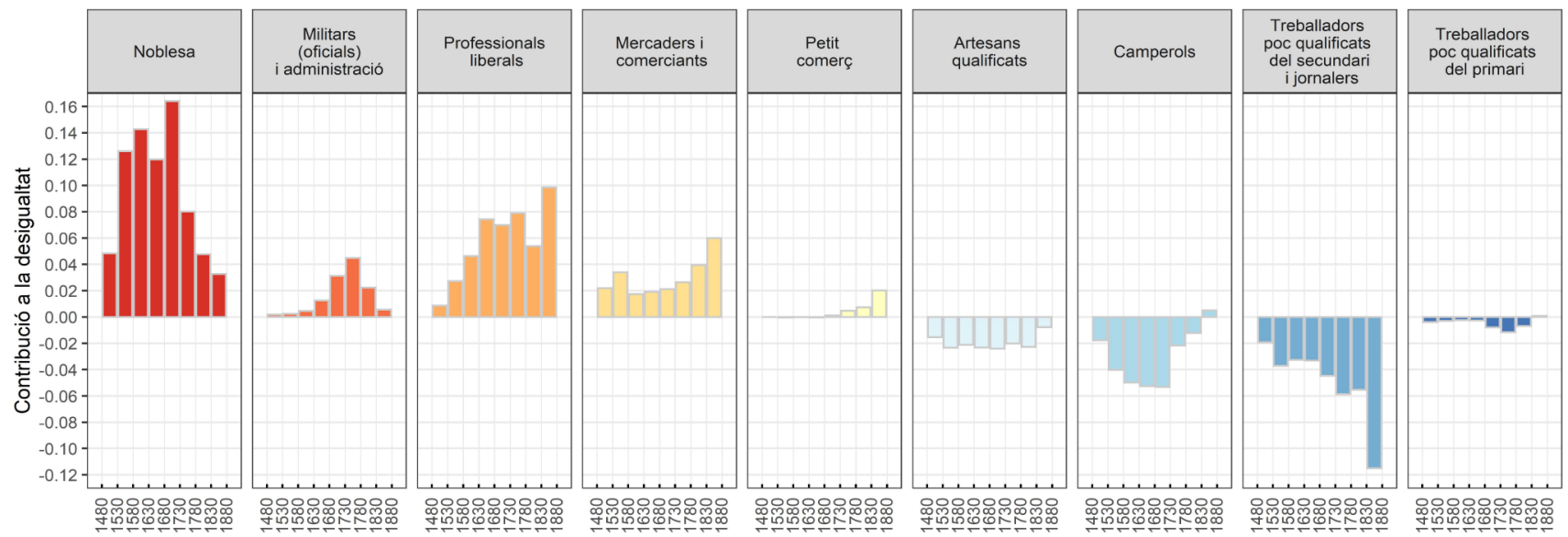

Nota: S'han conservat els noms dels grups socials que proporciona la classificació HISCLASS per tal de facilitar les comparacions. Com a conseqüència de la idiosincràsia de la noblesa s’ha creat un grup propi que l'anterior codificació no contempla. Font: BHMD i Brea-Martínez, Gabriel; Pujadas-Mora, Joana Maria (2019) "Estimating long-term socioeconomic inequality in southern Europe: The Barcelona area, 1481-1880." European Review of Economic History, 23 (4): 397-420. 


\section{QUI GENERAVA LA DESIGUALTAT EN EL PASSAT? NO SEMPRE VAN SER ELS MA- TEIXOS}

La Figura 2 mostra els grups socials que més van contribuir a la formació de la desigualtat econòmica al llarg dels cinc segles estudiats. La contribució a la desigualtat (positiva o negativa) es calcula a partir de la relació entre dos components específics: 1) El pes poblacional d’un determinat grup social sobre el total d'individus i 2) El pes de la riquesa del grup sobre el total d’impostos pagats. D’aquesta manera, quan la proporció de riquesa que acumula un determinat grup és més gran que el seu pes en la població, el grup en qüestió contribueix positivament a generar desigualtat. Per contra, quan un grup té un pes poblacional major a la riquesa que acapara, contribueix negativament a originar desigualtat.

Per simplificar l'anàlisi, hem agrupat les ocupacions / estatus en 9 grups socials a partir de la Historical International Standard Classification of Occupations (HISCO) i el Historical Social Class Scheme (HISCLASS) (van Leeuwen et al., 2002 i van Leeuwen i Maas, 2011). Només cal percebre la magnitud de les xifres per adonar-se’n que la noblesa i la burgesia (els professionals liberals o els comerciants, entre d'altres) contribuïen de forma important a generar la desigualtat ja que acumulaven relativament molta més riquesa que la resta dels grups. No obstant això, en el cas de la noblesa, la seva capacitat d'acumulació disminueix a partir del segle XVIII. Fins a 1730, un $45 \%$ de la desigualtat de l'àrea de Barcelona s'explicava per la influència de la noblesa. La burgesia i, més en concret, els professionals liberals, es consoliden en el segle XIX, convertint-se en el grup que concentra més riquesa. Tendència que s'albira, encara que en menor mesura, entre els comerciants.

Contràriament, els artesans, jornalers i camperols presenten valors negatius ja que el seu pes demogràfic és més gran que la riquesa que

FIGURA 3. Acumulació de riquesa de l'1\% més ric i la seva composicio social a l'àrea de Barcelona, 1481-1880

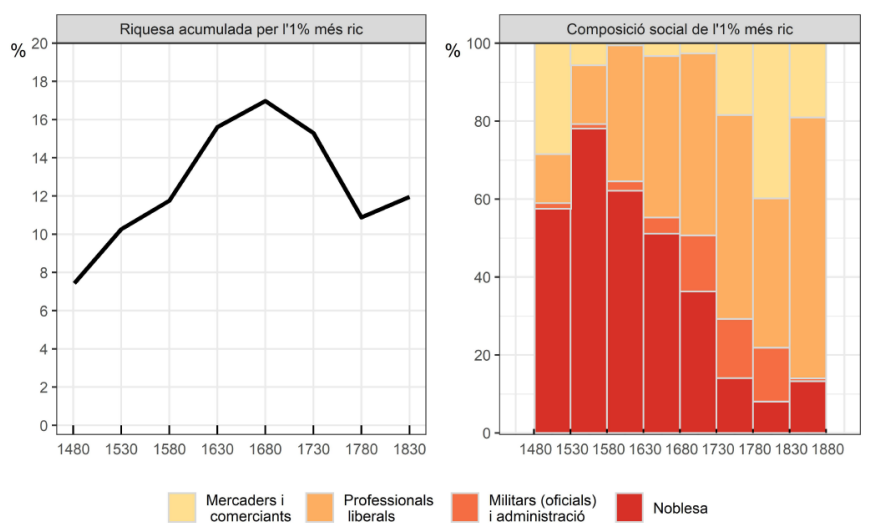

Font: $B H M D$. acumulaven. El coeficient negatiu dels treballadors amb baixa o nul·la qualificació s'incrementa al mateix temps que el seu nombre augmenta, arribant a explicar el 33\% de la desigualtat de l'àrea de Barcelona. A mesura que el nombre de camperols és menor, la seva contribució negativa disminueix. Els pagesos més desafavorits van passar a nodrir el sector industrial a partir del segle XVIII, quan s'accelera el desenvolupament econòmic. Els grups que van impulsar el creixement de la desigualtat estaven completament relacionats amb el sistema fabril: jornalers, teixidors, etc. Es tracten de grups molt nombrosos, però sense acumulació de riquesa, cosa que permet plantejar l'existència d’un procés de proletarització lligat a la desqualificació laboral.

\section{EL RELLEU DE LES ELITS ECONÒMIQUES}

L'acumulació de riquesa entre els més rics explicava en gran part l'augment de la desigualtat en època preindustrial, principalment des de finals del segle XVI i fins a la segona meitat de segle XVIII. La Figura 3 mostra la concentració de riquesa per a cada un dels grups socials en l'àrea de Barcelona durant aquest període: l'1\% de la població va passar d'ostentar un 10\% del total de la riquesa a gairebé duplicar-lo, a un 17\%, en la segona meitat de segle XVII, sent aquest el punt màxim. A partir d'aquest moment, la concentració de riquesa entre els tradicionalment més rics comença a baixar. L’acumulació de riquesa va ser superior en períodes anteriors a la consolidació de la industrialització i del capitalisme durant la segona meitat de segle XIX. De fet, els més rics van ser molt més rics durant el període preindustrial, encara que el desenvolupament del capitalisme permet majors nivells de concentració, no es pot oblidar que aquesta ja s'havia iniciat durant l'Antic Règim.

Per més que sigui important conèixer quanta riquesa posseïen els més rics, també cal saber qui eren socialment al llarg dels cinc segles que abasta l'estudi. A l’àrea de Barcelona podem classificar aquest 1\% més ric en quatre categories: nobles, militars i membres de l'administració, professionals liberals, i elits del comerç (mercaders i grans comerciants). Els nobles representaven més del 50\% de l'1\% dels més rics entre el segle XV i l'inici del segle XVII, tot i que el seu pes anà disminuint des de mitjans del segle XVII, fins a arribar al 10\% a finals de segle XVIII i el segle XIX, situació semblant a la que es va produir en països com França i Anglaterra, fins i tot en un període anterior.

El protagonisme perdut per part de la noblesa va ser majoritàriament capitalitzat pels professionals liberals (en un principi foren els doctors en lleis o en medicina). De fet, passaren de representar al voltant d'un $15 \%$ de l'1\% més ric en els segles XV i XVI a suposar les tres quartes parts a l'acabament del segle XIX. Els oficials de l'exèrcit i els membres de les diferents administracions públiques (real, Consell de Cent, universitats/ajuntaments, Diputació del General, etc.) integraven aquest 
grup, encara que el seu pes va ser bastant reduït, la qual cosa s'explicaria pel baix nombre d'individus que exercien aquestes funcions. Els grans comerciants constituïen l'últim grup que formava part de l'1\% més ric i el seu pes va anar incrementant-se a mesura que disminuïa l'acaparament de la riquesa entre els tradicionalment més rics. Aquest darrer grup significava un 30-40\% de la composició total d'aquest 1\% en el moment en què la concentració total de la seva riquesa es trobava al voltant del 10\%. Però si atenem al total de riquesa acumulada entre el 10\% més pobre (resultats no mostrats al gràfic) es pot percebre que en els períodes en els quals la centralització de l'1\% va ser menor, el total de riquesa d'aquest 10\% era més gran, al voltant d'un 7-8\% a les acaballes del segle XV i inicis de segle XVI, així com a la fi del segle XVIII. En canvi, quan el 20\% del total de la riquesa estava en mans de l'1\% més benestant, el 10\% més pobre només posseïa prop d'un 4\% del total.

\section{CONCLUSIONS: ACUMULACIÓ, DESPOS- SESSIÓ I SORGIMENT DE NOVES CLASSES SOCIALS}

En aquest estudi hem analitzat l'evolució de la desigualtat i la seva relació amb el sorgiment de nous grups socials a l'àrea de Barcelona per un període de cinc segles amb les dades de la Barcelona Historical Marriage Database (BHMD). Hem mostrat com els nivells de desigualtat en l'Antic Règim van ser superiors en comparació als de l'època industrial. El sol fet de copsar l'evolució de la desigualtat per a un període tan extens no té precedents en cap altra regió d'Espanya ni gairebé cap país europeu. Aquest treball no hagués estat possible sense la valuosa informació que proporcionen les dades recollides en la BHMD. Aquest és només un exemple del seu enorme potencial.

Els resultats constaten que els grups socials que van generar la desigualtat econòmica en el passat no sempre van ser els mateixos com ho evidencia la diferent contribució a la desigualtat dels distints grups. S’observa una clara divisió entre el període preindustrial i la industrialització. En les fases més antigues, la disparitat econòmica s'explicava principalment per la notòria contribució de la noblesa. Mentre que en els períodes més recents seria l'aportació negativa (l'empobriment) dels treballadors poc qualificats el que originava una major desigualtat. Estaríem parlant dels jornalers, una ocupació que no figura en els $\mathrm{Lli}$ bres d'Esposalles fins a finals de segle XVIII, quan observem un notable procés de proletarització que continuarà durant la industrialització. La composició de l'elit econòmica va variar en el temps. Aquest estudi aporta evidències empíriques i quantitatives de com la transició de l'antic règim a l'època industrial va suposar el bescanvi en el protagonisme dels grups més benestants, aquest passà de la noblesa a la burgesia. A més, l'anàlisi a llarg termini ha permès situar exactament en el temps quan es va produir el procés de substitució d'unes elits per unes altres. En aquest sentit, podem assenyalar que quan el pes de nobles i burgesos és semblant la desigualtat general s’intensifica més. Aquests resultats suggereixen que és justament en els moments de transformació econòmica i social quan les disparitats poden tenir un major impacte, un fet cabdal no només en el passat sinó també en el present, sobretot en un context en què la desigualtat no s'atura de créixer.
Referències bibliogràfiques

ALFANI, G. (2015) "Economic inequality in northwestern Italy: a long-term view (fourteenth to eighteenth centuries)". The Journal of Economic History, 75 (4): 1058-1096. https://doi.org/10.1017/Soo22050715001539

ÁLVAREZ, B.; RAMOS PALENCIA, F. (2018) "Human capital and earnings in eighteenth-century Castile". Explorations in Economic History, 67: 105-133.https://doi. org/10.1016/j.eeh.2017.10.005

BREA-MARTÍNEZ， G.; PUJADAS-MORA, J.M. (2019) "Estimating long-term socioeconomic inequality in southern Europe: The Barcelona area, 1481-1880". European Review of Economic History, 23 (4): 397-420. https:// doi.org/10.1093/ereh/heyo17

KENDRICK, M. S. (1939) "The Ability-to-Pay Theory of Taxation". The American Economic Review, 92-101.

MULANOVIC, B., LINDERT, P. H. WILLIAMSON, J. G. (2011) "Pre-industrial inequality". The Economic Journal, 121 (551):
255-272. https://doi.org/10.1111/j.14680297.2010.02403.x

PIKETTY T. (2014) Capital in the 21st Century. Cambridge: Harvard University Press.

PIKETTY, T. (2020) Capital and Ideology. Cambridge: Harvard University Press.

REIS, J. (2017) “Deviant behaviour? Inequality in Portugal 1565-1770". Cliometrica, 11 (3): 297-319. https://doi.org/10.1007/s11698-0160152-7

VAN LEEUWEN, M. H.; MAAS, I. (2011) HIS CLASS: A historical international social class scheme. Leuven: University Press.

VAN LEEUWEN, M. H.; MAAS, I.; MILES, A. (2002) HISCO: Historical international standard classification of occupations. Leuven: University Press.

VAN ZANDEN, J. L. (1995) “Tracing the beginning of the Kuznets curve: Western Europe during the early modern period". The Economic History Review, XLVIII (4): 643-664. https:// doi.org/10.2307/2598128.
Cita

Joana Maria Pujadas-Mora i Gabriel BreaMartínez (2020) "Cinc segles de desigualtat i transformació socioeconòmica en l'àrea de Barcelona, 1451-1880". Perspectives Demogràfiques, 18: 1-4 (ISSN: 2696-4228) https://doi. org/10.46710/ced.pd.cat.18

ISSN

ISSN: 2696-4228

Editors

Andreu Domingo i Albert Esteve (Centre d'Estudis Demogràfics)

Correspondència dirigida a:

Joana Maria Pujadas-Mora jpujades@ced.uab.es

Crèdits

Gràfics: Anna Turu

Maquetació: Xavier Ruiz Vilchez

Agraïments

Als editors per convidar-nos a realitzar aquesta publicació i pels comentaris aportats durant el procés d'elaboració A Anna Cabré per creure en nosaltres. Aquest treball ha estat finançat a través dels projectes "Condicionants demogràfics de la desigualtat econòmica, una aproximació històrica (segles XVIII-XX)" (RTI2018095533-B-Ioo) i "Five Centuries of Marriages" (ERC-2010-AdvancedGrant -269796).

Enllaç url

http://ced.uab.es/difusion/butlletiperspectives-demografiques

Contacte

Centre d'Estudis Demogràfics. Carrer de Ca n’Altayó, Edifici E2 Universitat Autònoma de Barcelona 08193 Bellaterra / Barcelona

Espanya

Telèfon: +34 935813060 Correu:demog@ced.uab.es Web: http://ced.uab.es/

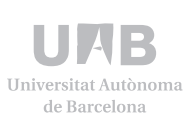

